\title{
Perceptions of Graduate Students and Supervisors on the Effectiveness of Chinese EFL Academic Socialization: Interview Results
}

\author{
Hongbing Peng \\ Correspondence: Hongbing Peng, Institutional Affiliation: College of Foreign Studies, Jinan University, China
}

Received: February 14, 2016 Accepted: March 7, 2016 Online Published: March 25, 2016

doi:10.11114/jets.v4i6.1360

URL: http://dx.doi.org/10.11114/jets.v4i6.1360

\begin{abstract}
The paper explores the perceptions of graduate students and supervisors on the effectiveness of Chinese EFL academic socialization through an interview study from the perspective of Discourse System (DS) proposed by Scollon and Scollon (2000). The investigation, which was conducted in one leading Chinese university of foreign studies in 2010, was participated by 24 graduates and 13 supervisors. The results revealed that both students and supervisors were dissatisfied with the inadequate supervision, unstructured tutorial and unmanaged time in the process of supervision. The study implies that the non-bureaucratic administrative system, which is exemplified by no division of supervision power, informal and relaxed supervision and an absence of detailed and explicitly stated rules and regulations to regulate and restrict supervision behavior and supervision practice, serves as the greatest limiting factor which hinders the professional development of individuals and adversely affects the effectiveness of academic socialization. It is suggested that a pro-supervising research community should be designed to enable its students to generate quality research outcome and its supervisors to focus on academic duties only.
\end{abstract}

Keywords: perceptions, graduate students and supervisors, effectiveness, Chinese EFL academic socialization, discourse system

\section{Introduction}

The earlier study (Peng, 2015) reveals that in the past decade, increasing nationwide social and academic attention has been paid to the quality of research supervision as a whole in mainland Chinese graduate education, especially problematic supervisor-student relationship characterized by paternalistic leadership style. Supervision complaints, related factors, measures to address the complaints and solutions to establish effective supervisory relationship have been discussed as well. It can be seen that traditional supervisory relationship is much affected. Regardless of useful insights over the causes of problems and helpful suggestions to manage the supervisory relationship from ethical, educational and administrative perspectives in the Chinese academic context, the problem still remains unresolved with the existing measures.

The above studies raise the following questions:

1. Why do supervision events take place in today's China one after another?

2. Should public opinion criticize from merely an ethical perspective?

3. Was the supervisory relationship over reliant upon ethnical discipline in the past?

4. Is the worsening supervisory relationship due to lack of laws or absence of detailed regulations which can protect the rights and obligations of both supervisors and supervisees?

5. How to set up a system to offer solutions or to make improvements?

The supervisory relationship is a historical issue and long-term issue. It is high time to call for this kind of study, and it is high time for the society to get to know this issue, find reasons and offer guidance. So there is a pressing need to identify and examine the significant limiting factors that give rise to the problematic relationships in the graduate education.

The current research is intended to achieve the above objective by examining the effectiveness of graduate students' academic socialization in Chinese EFL research supervision. In-depth interview will be applied as principal research method to analyze and interpret the factors which become the strongest influence in the relationship in a Chinese EFL 
research community of practice (Wenger, 1998) located in a developed province of southern China from the perspective of Discourse System (DS) proposed by Scollon and Scollon (2000). This broader intercultural communication framework instead of traditionally narrow ethical and educational perspectives will help analyze the hidden complexities in the community of practice which might endanger the relationship and thus negatively affect the quality of education and hamper the progress of graduate education reform in the long run.

\section{Literature Review}

According to $\mathrm{Li}$ and $\mathrm{Xu}$ (2006), Chinese EFL (English used as foreign language) graduate education started after 1949, but developed quickly after the $21^{\text {st }}$ century. Admission of students was resumed in 1977, and enrollment restarted in 1978. The degree system was implemented in 1981. Only seven universities and research institutes were entitled to award English doctoral degrees then, including Beijing University and Beijing University of Foreign Studies. However, by the end of December 2005, as many as 21 doctoral awarding bodies were set up all over China. There are six English graduate programs included, such as English language and literature, linguistics, applied linguistics, English for specific purposes, comparative literature and translation theory and practice. By 2007, approximately 8,100 EFL postgraduate students and 333 doctoral students were enrolled annually by Chinese higher education institutions (Zhang \& Yang, 2009).

\subsection{EFL Research Supervision in China}

Much earlier relevant study has concentrated on such facets as program catalogue, supervision plan, admission, supervision process, common problems and suggestions.

In supervisors' opinion, those aspects such as knowledge, abilities to find, analyze and solve problems (Hua, 2000a; Lu, 2001; Gao, 2012), language foundation, research competence (Dai, 2000), research interest and creative thinking (Lu, 2001) needed to be considered in selecting students.

The ways of how to supervise has been discussed extensively, including selecting topics (Lu, 2001; Hu, 2002), acquiring broad knowledge (Hua, 2000a; Hua, 2000b; Lu, 2001; Hu, 2002), fostering independent, rigorous, logical thinking abilities, developing creativity and abilities of understanding and solving problems (Dai, 2000, Lu, 2001; Wen, Ding, Chen, \& Wang, 2006; Wang, 2008a), having extensive reading and regular discussion (Hua, 2000a), writing research paper (Hua, 2000a; Zhu, 2003), handling disagreements (Hu,2002), introducing collaborative-inquiry model into the teaching (Dai \& Wang, 2005), building learning community (Wen et al, 2006),cultivating students' advanced level thinking competence through providing the course entitled "Literature Reading and Assessment"(Wen, 2008), and developing academic competence of students in the process of supervision regarding evaluation, self-access, curriculum design, supervisors, and teaching materials (Dai \&Wang, 2007; Wang, 2008a, 2008b, 2009a, 2009b, 2010, 2012, 2013, 2014).

\subsection{Common Complaints}

Common complaints in EFL Chinese research supervision are related to the areas of research students, supervisors, graduate education and graduate supervisory system.

Major complaints with research students could be found out as: they could not distinguish authors' views from others' views (Wen, 2008); some supervisees admired international magazines blindly without ever thinking of questioning, and logical relations were confusing in dissertation writings (Wen, 2008); independent thinking ability was poor, let alone creative and cross-disciplinary research abilities (Wen et al, 2006; Sun, 2008; Dai, 2009; Wang, 2010); other students did not study hard and just wanted to graduate as they were busy doing part-time jobs (Dai, 2000; Dai, 2009); and still other students were unable to choose what was to be learned and how to develop themselves on their own (Zhang, 2005); their knowledge was limited (Sun, 2008;Dai,2009;Wang, 2010).

Major complaints with supervisors have been examined. Some supervisors were held to lack supervisory competence while the others were considered as short of research competence and academic integrity (Zhang \& Yang, 2009).

EFL graduate education is deemed to blame. There was a separation between course study and dissertation writing and there is a tendency with emphasis on results instead of process (Wen, 2002). Research quality objectives were empty, which did not help their implementation and examination (Wen, 2002). Teaching methods were rigid and teaching content was outdated (Sun, 2008). There was an emphasis in knowledge instruction, but a lack of education in research ethics and academic integrity so that plagiarism occurred frequently in graduate education (Dai, 2009); there was emphasis in standards of form, but neglect of definition of objectives in doctoral education (Zhang \& Yang, 2009); there was emphasis in degree courses, but neglect of interdisciplinary research methodology (Zhang \& Yang, 2009); curriculum design was unsatisfactory, with emphasis on theory rather than methodology and teaching rather than research (Wang, 2009a).

The graduate supervisory system is regarded as responsible as well. Traditional apprentice-master model limited students to learn from others (Wen, 2002); the supervisory model needed to be improved (Zhu, 2005; Sun, 2008; Dai, 2009); the 
entrance examination was imperfect, in which scores were emphasized, but comprehensive qualities such as analytical, responsive and expressive abilities were ignored (Dai, 2009); exit system was not realized in its true sense, as it was just a display (Dai, 2009); students had fewer chances of attending conferences home and abroad, so they were academically narrow-minded and lacked adequate consciousness of academic frontline (Dai, 2009); there was a separation between supervisory objective and social demand, as some graduates did not do research after graduation, but did other jobs in companies (Dai, 2009); there was a lack of truly effective evaluation system and a lack of communication between universities (Dai, 2009); there was an emphasis in supervisor team construction, but a lack of inspection of supervisors' academic integrity (Zhang \& Yang, 2009).

\subsection{Major Suggestions}

Major suggestions were proposed to address the above mentioned problems from the perspectives of graduate education and administrative system.

As for the graduate education, the following suggestions have been offered: develop students' creativity (Zhu, 2005; Sun, 2008); reform existing textbooks, teaching methodology, perfect MA thesis writing, and standardize graduation thesis format by borrowing supervisory styles from foreign countries (Zhu, 2005); nurture research competence required of students (Zhu, 2003;Wang, 2009a, 2009b); renew teaching philosophy and methodology, finalize supervisory objectives of research quality for different stages of study, reduce time for language skill and strengthen training of thinking in Chinese courses, open communicative thesis writing seminars and team-teaching courses; adopt group collective report, reform evaluation system with emphasis on both process and result (Wen, 2002; Wen et al, 2006); redefine supervisees' role as plan designer, practitioner, reflector and evaluator, and supervisors' role as mentor, facilitator, and discipliner (Wang, 2008a).

As for the graduate administrative system, it should be improved in the following ways: stabilize admission scale, emphasize supervision quality, strengthen construction of supervisor team, replace apprentice-master model with supervisor responsibility system (Wen et al, 2006); set up supervision committee, design evaluation system, invite experts outside school to have a comprehensive evaluation of dissertation by means of blind peer-review (Zhang \& Yang, 2009).

\subsection{Summary}

In short, the prior studies with respect to EFL research supervision have shown the vital role of effective research supervision in the Chinese EFL academic contexts. It has highlighted the existing academic, educational and administrative problems in the Chinese EFL research communities of practice. It signals a critical need to handle the existing supervisory problems in the Chinese EFL research context. The review indicates that there is an over reliance upon moral, educational and administrative measures to regulate and restrict supervisory behavior in the Chinese academia and the supervisory problems remain unsettled despite ample academic discussion.

Moreover, no specific theoretical framework is employed for analysis and interpretations except one study of integrating related theories of linguistics, psychology, second language acquisition and education into the study of research student's academic competence (Wang, 2010). The studies comprise supervisors' perceptions only, but a few students'.

Finally, methodologically speaking, existing studies are mainly based on experience summary and speculations with the exception of one empirical study (Wang, 2010). There is an absence of systematic qualitative study of research supervision in EFL research context. The former related studies are quantitative to a considerable extent.

Consequently, relevant earlier studies afford the justification for the present study to describe and explain the effectiveness of research supervision through perceptions of students and supervisors in terms of the academic socialization in the Chinese EFL research community of practice.

\section{Research Questions}

Based on the above, the following research questions are put forward for the present study:

RQ1: How was supervision perceived?

RQ2: How was tutorial structured?

RQ3: How was time managed?

\section{Theoretical Framework}

The present study will be conducted under the analytical framework of Discourse System (DS hereafter). DS consists of four significant constituting elements like ideology, socialization, forms of discourse and face system (see figure below). Of the four essential components, ideology is positioned at the bottom and considered the first as it is believed to have the strongest influence upon the other components of the discourse system, especially the forms of discourse on 
the top. "It is-a kind of self-contained system of communication with a shared language or jargon, with particular ways in which people learn what they need to know to become members, with a particular ideological position, and with quite specific forms of interpersonal relationships among member of these groups"(Scollon \& Scollon, 2000: 95). DS, which is much broader, deeper and systematic than the earlier moral, educational and socio-cultural frameworks, is expected to help identify the significant contributing factor that inhibits effective research supervision in the Chinese supervision system.

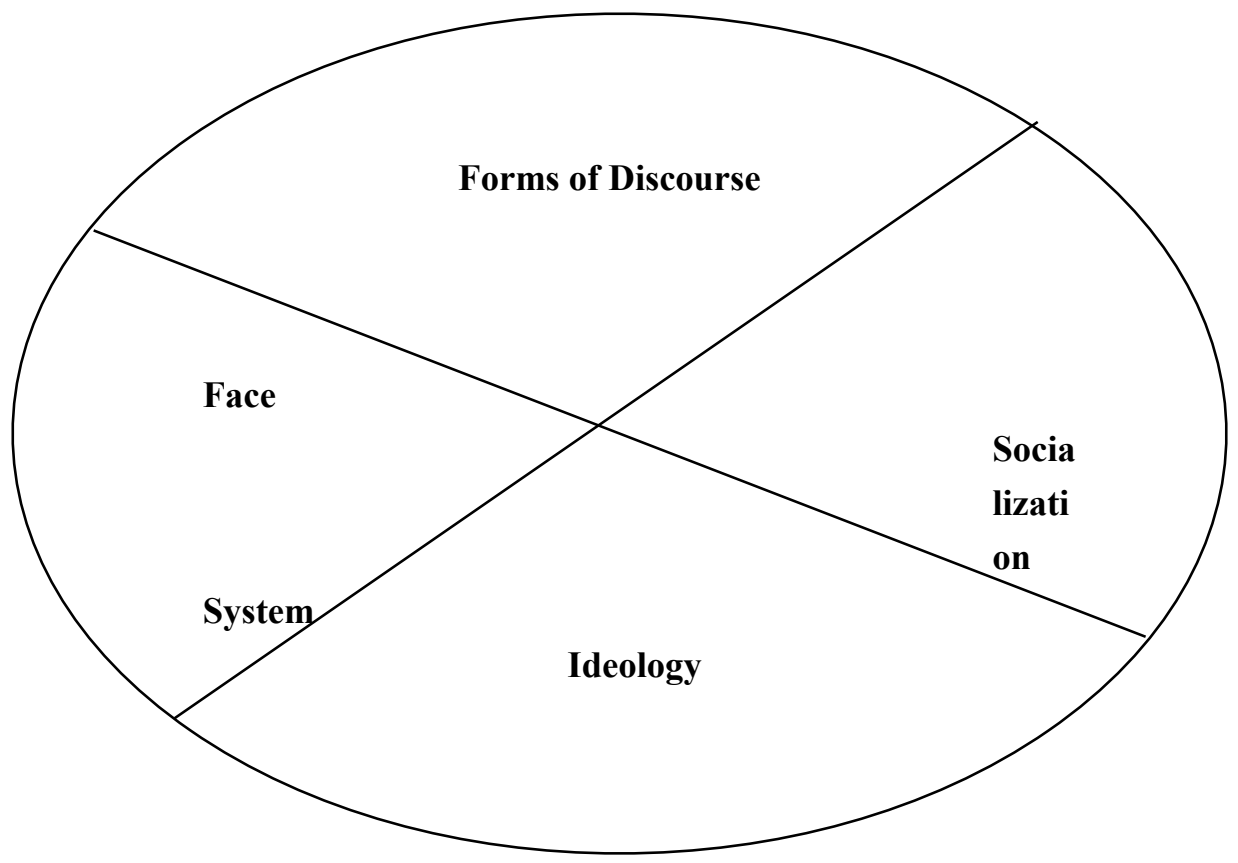

Figure 1. Discourse System

\section{Method}

The present study will employ interview research, "with the transcribed recordings analyzed by qualitative content analysis" (Dornyei, 2007: 24), as the major research method.

\subsection{Research Site}

U/C (note 1), a nationally renowned university of foreign studies located in one capital city of south China, was selected as the research site for the current study due to such reasons as economically favorable location, academic internationalization and strong research foundation.

\subsection{Research Informants}

Twelve $\mathrm{PhD}$ supervisors and one MA supervisor of U/C participated in the study. All of them have obtained their $\mathrm{PhD}$ degrees in mainland China or in Hong Kong or in the English speaking countries. They teach various courses in the areas of literature, linguistics and translation. Some of them are nationally-renowned EFL experts or leaders. Building trust with most of them was undertaken after the researcher's PhD admission and before interviews mainly through the following ways: attending their courses, tutorials, academic lectures and viva if they had in the school during her investigation, several times or a whole semester. But the rest of supervisor informants were contacted by mentioning the name of the researcher's supervisor whom they knew very well. This shortened the distance because of the Chinese insider culture.

$24 \mathrm{U} / \mathrm{C}$ graduates took part in the investigation. Of them, there were $6 \mathrm{MA}$ holders and $18 \mathrm{PhD}$ holders. They were chosen from different research areas to give a balanced view of the subject matter. By the time of the interviews, all the informants had graduated from U/C. One rationale behind such sampling strategy is the researcher's belief that graduates can make better sense of their lived experience as graduate students. Another reason involves the consideration that Chinese graduate students dare not complain about their supervisors during their study for fear of being unable to graduate because of their powerless position. Most of the student informants have been friends of the researcher for at least six 
years, and they both have many interactions in academic and non-academic matters. So a good rapport has already been established between them before interviews to ensure the reliability and validity of the data.

\subsection{Research Instrument}

The instrument used in this research for all student and supervisor informants are made up of three parts, an interview guide, an informed consent and a copy of interview questions (See appendix). All were in Chinese. The interview guide is a letter addressed to supervisors and supervisees separately, informing the nature, purpose and scope of investigation, and the confidentiality of their identity and information. The informed consent is to inform the informants the title, investigator and time of the investigation. It also informs interviewees of the voluntary nature of their participation and their freedom to refuse to answer any questions to specific items in the semi-structured interview, or withdraw their consent and termination of their participation anytime. The two parts were adapted from S. Wang's study (2008). The interview questions co-administered by the researcher's supervisor and the researcher herself in Chinese includes 32 questions. The questions made detailed inquiries of academic and non-academic interactions between students and supervisors in the supervision process. They were used by both of them.

\subsection{Data Collection}

In-depth interview, the major investigation method for supervisees and supervisors, formally began in June 2010 and lasted until December 2010. Most of the interviews were conducted once, with a few three times, followed up by triangulations in the form of emails now and then from 2011 to 2014. Before the interview, the recording devices like one MP3 and one recording pen were taken out with the consent of interviewees. They were put nearby to have a clear recording, but not so visible to both parties because of their small size. All the questions and answers were conducted in Chinese, which both informants and researcher felt comfortable with. Most interviews were conducted on one-on-one basis at office or dorms while some via emails to save time. The total length of interview time for the supervisors reached more than 22 hours and transcripts of Chinese text amounted to 235, 220 Chinese words. The total time for the recording of students was more than 21 hours. And the total transcripts in Chinese text amounted to 287, 261 Chinese words. Besides, web-based interviews with some supervisees were carried out via email. This type of data amounted to 24 , 530 Chinese words. The data collected from both groups is used for the purpose of triangulation in the study.

\subsection{Data Analysis}

In terms of data transcription, the recorded spoken data was first of all transformed into textual forms by hand. All the verbal interviews, including re-interviews, were transcribed verbatim in Chinese texts by following the conventions summarized by Richards (2003: 173-174). Every recording was hand-played in the computer by using the software. Each recording was generally listened to three times, followed by coding procedure. First of all, two files were set up for datasets of supervisees (three odd digital code 1\#\#) and supervisors (three even digital code 2\#\#). Next an individual subfile was set up for each informant identified with a code. The data source has been illustrated in the text by using, for example, \#101 meaning the interview data of student informant No.1, \#210 meaning the interview data of supervisor informant No.10, and \#111C meaning the third interview data supervisee informant No. 11 has. Finally, when it came to presenting the research results, the researcher translated all the needed transcribed Chinese texts into English in order to present the research results in the article.

\section{Results}

The results that are to be presented below are a part of the larger investigation the researcher completed for her $\mathrm{PhD}$ dissertation in 2014. What follows will report what Chinese EFL graduate supervisors and students complain most about their students and supervisors. The views claimed by the supervisor and students informants are considerably reliable and directly and indirectly expressed in the interviews. It is very important to bear in mind that many graduate students have said they have got good supervisors in their supervision, so do the supervisors of their students. Therefore, the following negative comments should not be used to refute this point. It is simply because of the researcher's purpose in this study that the negative comments are focused upon.

The perceptions of supervisors and students towards their academic socializations are explored, which point to the dissatisfaction of graduate students and supervisors towards their research supervision. The results of the study can be summed up in the following three aspects, including inadequate supervision, unstructured tutorial, and unmanaged time.

\subsection{Inadequate Supervision}

The students' data showed that in earlier times doctoral students were unable to have their proposals passed in their third year of $\mathrm{PhD}$ study because supervisors were too occupied to offer supervision. The supervision was inadequate. This usually happened to two groups of supervisors: those who were too occupied with either their own research project or administrative commitments to have time to supervise and those who were reluctant to offer time to supervise students. In their views, students should learn how to do research independently. This was found more with MA supervisors than PhD 
supervisors. Supervisee $\mathrm{X}$ recalled:

Our classmates generally held positive views of instructional effects of most [MA] instructors in U/C. As far as supervisors are concerned, most of the students thought they were too busy to supervise students' theses and to have time to contact students, though most students thought their own supervisors were very nice. (\#124B)

In one word, the supervisors were unavailable due to their own commitments. Nevertheless, in the process of writing, when students were confused about ideas, or lost in directions, or struggling hard, they longed for chances to communicate with their supervisors, but because the latter was inaccessible, it was hard for both to sit down together to have discussions frequently. As a result, the following cases happened: students were unable to see their supervisors very often; students submitted their thesis to their supervisors, but after two months or three months, there was no feedback from them, or supervisors responded but told their students to revise again. In one extreme case, the feedback was given, but that was six months later.

Compared to the above cases, there was a more devastating story, as supervisee $\mathrm{X}$ recalled her supervisor's response to her thesis with bitterness:

Think about what you can expect to find from xxx, what you find, and also mind those you have not found at the same time, those studies which predecessors have found much earlier (giving a special distinction of this in your language expressions); including thinking about the questions in your last email, which will be beneficial to you; unfortunately I can't discuss these with you in the email, because this is very complicated, my time is limited. For this reason, $I$ certainly disagree having a meeting with you during summer holiday. I told you I had no time, but you still asked me "Are you available?" I don't understand if you really listen to my advice seriously? (Italics are for emphasis).

I felt wronged: my research proposal must be turned in the second week after the new semester began; it was already 21 August when he responded, but at that time, I still did not have a clear conceptual framework of what to write, so I was anxious to meet him face to face, but his attitude was such... (\#124B)

In student' mind, academic integrity was regarded as the top attribute of supervisors' assumed qualities. However, it was beyond them why some supervisors left them alone after registration. One supervisor confirmed that some supervisors were professionally immoral. Some were power-disowned, letting supervisees do whatever they wanted so that students were unable to graduate on time owing to procrastination. One senior supervisor said:

There is a big difference between supervisors about what is supervision. Some are just power-disowned, saying my own supervisors just do it like this, while the other supervisors say doctoral students should do everything. There is a very big divergence over how to supervise. Some are very strict, just like me, who is very unpopular among students, while the others who are "lao hao ren" (a benign person who is indifferent to matters of principles), or who are easy to let students pass, are so popular that students are eager to find them. So this is a problem, this is a problem, namely, inconsistency of quality, so it is hard to say, it is hard to say. (\#210)

The data also confirmed how supervisors spent their time in U/C. They are very hectic these days as a consequence of increasing demand of their time and efforts from routine teaching, supervision and research responsibilities. As for teaching, they need to give lectures not only to graduate students but also undergraduate students for no less than six teaching hours a week, mark homework, final examination papers and thesis, and report the final marks to the school at the end of semester; they need to attend teaching-related departmental or college meetings sometimes.

As regards supervision, they needed to prepare written examination papers for new candidates at the beginning of the year, mark and report the results; they needed to give interviews to candidates before a final decision was made concerning their candidature; they needed to supervise not only a few MA students but also one or two doctoral students and several visiting scholars arranged by the school every year; they needed to design individual supervision plan for students and monitor its implementation (in reality, this step is done by students themselves); they needed to lend books or borrow or copy books for students in earlier times when book resources were scarce; they needed to make booklists available; they needed to have one-on-one conference with their students occasionally, in which individual supervision was actually flexible according to different stages, availability and willingness of supervisors and students, but not done twice a week as stated, mostly through emails, phone calls, lectures and collective tutorials; they needed to supervise students on issues over topic selection, research design, pilot studies, analytical framework, theoretical concepts, research direction, research methods, research skills, statistics, research ethics, thesis format and the like; they needed to send e-articles and e-books to their students when in need; they needed to read drafts of dissertations, revise drafts several times, send emails back and forth to students about their suggestions; they needed to discuss thesis face to face with students when they were in need; they needed to consider students' future professional development; they needed to inform their students of some important academic lectures; some supervisors needed to do experiments with their students by helping contact subjects and prepare survey materials and gifts for their informants; some supervisors needed to take their students to do 
on-the-spot research and stayed at the site for a period of time; they needed to prepare for the list of potential external examiners for thesis defense of their students; they needed to attend the research proposal defense, pre-viva and viva of not only their own students but also the students of other supervisors every semester; they needed to attend dinners with students or attend dinners of their graduates; they needed to lend money to full time students if they were in financial difficulties in the past.

With regard to research, they needed to apply for research projects at different levels: school, province, ministry and nation; they needed to organize team members to do and finish the projects; they needed to do their own research by publishing their research results in reputed journal articles at home or abroad; they needed to publish books; they needed to give lectures inside and outside school; they needed to attend national and international conferences; they needed to review journal articles as editors; they needed to write book reviews if asked to.

\subsection{Unstructured Tutorial}

Some supervisees admitted that their supervisors pushed them forward in academic issues, by agreeing with students, forwarding their own opinions based on those of students or asking them more specific questions from different perspectives, namely from higher or further positions. They were good at pushing students to deeper levels, somewhere not thought of or ignored before. Moreover, they would ask students' progress in topic selection, proposal writing, data collection and draft. Yet, supervisors received complaints for not pressurizing students to make academic progress though they were very responsible. Supervisee J said:

How nice were some supervisors! XXX even invited her students to dinner at her own expense. My supervisor looked very serious, how couldn't I make a comparison? Though I felt somewhat a sharp contrast psychologically, my supervisor was unlike xxx either, he was outgoing, I feel he was outgoing, he was easier to approach than my supervisor, I feel. He would give some pressure to students and asked them to do things. I hope my supervisor would be like this. (\#110A)

She gave an example to illustrate this point. In the tutorial, in fact the supervisor was very responsible, possibly more responsible than others, as he would like his students to learn something, but one of his shortcomings was not to give students pressure. By contrast, $\mathrm{xxx}$ or xxx would ask students to do things directly. That is to say, they gave every student an opportunity, namely this week, A talked, next week, B talked, and next week, C talked. But her supervisor was always afraid of hurting someone, since he thought if students liked to talk, just talk, if not, that was all right. Students were likely to have no chance to talk during three years.

But in fact, the student was not encouraged without pressure, because no pressure, no work, she was not encouraged in some aspects. Actually, he might as well give students some pressure without minding students' faces. They were student and supervisor after all and it was for the student's own good. Maybe she did want to talk, but felt pressurized by his authority, or other students. As far as she or other students were concerned, she dared not talk, or she could understand while others talked. It was not that she was unwilling to speak, but that she didn't have a chance to speak. She was not sure if he sensed that, but he always asked why their tutorial was so boring. That was where the problem was. If he asked everyone to host a tutorial every week, he asked questions, and the rest acted as evaluators. Things would make a difference, and everyone gained. She thought this had something to do with his personality, which was unorthodox: no pressure, no embarrassment, and no harm for all. In fact, it was not the case. In her view, as a student, there was no embarrassment at all because all were adults. This was not something against students, and they talked about academic matters. It didn't matter if they said wrong. In this way, she said little in tutorials. As she put:

We often had tutorials, but seldom did I speak, my supervisor never took initiative to ask me to speak. In addition, I'm self-abased, so I never had presentations like other peers, but in private, I would like to do it, I would like to express my opinions on certain issues, I often discussed with xxx, my thoughts became mature through them and I became more confident. But professor xxx didn't notice this. I think he should have forced students to do presentations at least once. I believe if he made me do it, I was sure to do it, and was sure not to do it unwell. Unfortunately he never asked me to do it, my laziness and self-abase made me forever give up such opportunities. (\#110D)

For good reason, the tutorial is not well structured by the supervisor. There is no clear message form in it, with neither set agenda nor open agenda. Not every student can be given an opportunity to make presentation like that of other tutorials. So, supervised $\mathrm{J}$ felt no push or no pressure.

\subsection{Unmanaged Time}

When it came to time planning on the side of supervisors, the students' views were divided. According to them, some supervisors managed their time very well, including managing their own work and students' dissertation in a well-planned way, as supervisee B commented: 
My supervisor sent me emails right after one week of admission, asking me to make plan for study and research. After entering school, I found he offered supervision based on individual differences. His supervision plan varied with different students. In the meantime, he followed up students' research progress in real time to see if theirs matched with his. This was very helpful for students to ration and make use of their time, and to develop and push their research progress forward. (\#102D)

However, MA supervisee $\mathrm{V}$ held an opposite view on this point, according to him, time management was relatively loose on the side of supervisors in $\mathrm{U} / \mathrm{C}$ :

In terms of time management, supervisors would discuss progress of thesis with us regularly, but did not give the agenda of thesis writing. In this sense, [time] management was relatively loose. If personal factors (such as finding jobs, preparing for $\mathrm{PhD}$ entrance examination, even family reasons) are involved to delay thesis writing, they are likely to lead to students' inability to complete thesis in time. (\#122A)

In supervisee K's opinion, poor time management resulted from the fact that supervisors did not spend enough time comprehending students' research design carefully.

Supervisors sometimes propose this opinion, sometimes an opposite opinion, which makes it hard for students to follow. In addition, they do not have a macro plan tailored to individuals, that is, within what time to complete what stage of tasks, which make students' progress slow and ineffective. (\#111B)

Supervisee F explained, supervisors would not keep an eye on students' time discipline on purpose. Sometimes, they would take chances to ask students indirectly, as they found it embarrassing to ask it in front of students, who were adults caring for face anyway. But supervisee A disagreed, in his opinion, the fault lay with supervisees instead of supervisors, as he put it:

In my knowledge, it is mainly because students cannot follow supervisors, they have their own plans. For instance, they hope their student can hand in proposal this semester, but student cannot do it as always. Supervisors say if he can hand in a draft at this time, he can't. That is, he can't follow, if he is unable to hand in, he cannot give a detailed plan. (\#101)

All in all, in students' opinion, supervision should be planned by supervisors rather than self-managed by supervisees alone. A combination of supervisees' own plan with supervisors' was conducive to successful graduation of supervisees.

The supervisors confirmed this point. They told that some students were under criticism to procrastinate in their dissertation writing as long as seven years, which was made as the deadline policy. There were two cases in this situation. In the first case, some students had a tendency to procrastinate: they were late in every stage, research proposal, first draft, and revision. The supervisors claimed they wouldn't admit students with such a tendency in the coming years. Supervisor 9 gave an example:

One student I learned later, later I learned, he couldn't hand in his thesis until deadline even as a MA student. Unfortunately I didn't know this in admitting him. This has implications for subsequent admission, that is to say, if a student has a tendency of procrastination, I won't admit him. When it comes to submitting writing, I suffer, so does he. (\#209)

In the second case, some students left school to work in a new work unit when their first drafts were not finished yet in the third year, at this time, they were not sure of how much of their time could be spent on the writing. In a new workplace, new work, new environment, they had to teach and familiarize themselves with them at the same time. They couldn't concentrate on their writing. They could have finished the writing within four years if they had been at school. But they needed to extend one or two or even longer time to finish it.

The student informant verified by saying that in the orientation session right after newcomers were admitted, they were always educated by giving a negative example: a student handed in his first draft only one month before the pre-viva defense. The teacher revised and sent it back, but the student never responded, as the latter was too casual to give a look at the revised thesis. He was unable to graduate punctually at last. In another example, one supervisor who was very responsible felt tired of supervising students, especially MA students. For instance, the graduation time was June, their thesis must be handed in April, then in March, the thesis couldn't come out, so his supervisor always had to keep on urging them to hand in the thesis. These things happened often, so he felt very tired of these. Later, he would rather not admit students. He was frightened.

The data revealed that some students procrastinated owing to a lack motivation to pursue a $\mathrm{PhD}$. Their supervisors attempted to provide intellectual energy, in terms of ideas, suggestions and strategies to enthuse them by pointing out the progress they had achieved, the validity of the research topic and the importance of research degree completion for career prospects. Or they tried to boost students' confidence by stressing their own belief in the project and in the students' 
intellectual capacity to conduct a doctoral level inquiry, in order to help create and maintain the impetus of the project.

For those reasons, supervisors needed to discipline students by asking their students to make a detailed schedule and by monitoring their progress regularly, lest their students "disappear from earth" for months on end before thesis submission deadline as described above and those students lacked self-discipline due to young age. Some supervisors were loose in all stages while others were very strict at the beginning and loose in the end vis-à-vis time management.

\section{Discussion}

As can be seen from the above, both students and supervisors are dissatisfied with certain aspects of EFL graduate supervision. To begin with, supervision is inadequate which arises from unavailable supervisors who are professionally immoral despite students' academic needs as a result of their own obligations. Second, the tutorial is unstructured. There is no push for academic progress from supervisors due to poor organization. At last, time management is loose due to inadequate attention paid to students' research design on the part of supervisors and students' poor management of research project as well. The students tend to procrastinate as a consequence of lack of research momentum and job hunting before finishing dissertations.

The dissatisfaction with the effectiveness of academic socialization from both students and supervisors indicates the following problems which need to be addressed.

First, power is so clearly identified with one supervisor that there is no division of supervision power based on "functional specifications". There is an absence of academic backing from the community as a whole to help students do research well ranging from learning support center, writing center, language center, counseling service, career service, IT service, administrative service, and domestic affairs services which are obtainable in the western research community of practice (European Institute of The London School of Economics and Political Science, 2011/2012). Supervisors, library and peers are the sole sources of academic support for students when in need after registration. Should any problems arise regarding lack of poor writing abilities, inhibition, lack of intellectual confidence, low research momentum, psychological crisis, financial difficulties, employment qualms, domestic affairs and so on, they have nobody to seek advice but their supervisors and peers. This is one of the great limiting factors to the growth of graduate students and the graduate education in the long run, and a cause also of much frustration of supervisors.

Second, supervision is conducted in an informal and relaxed style. There is a lack of supervisors' training workshop instituted to develop supervisors' supervision skills and methodological skills to address issues over inadequate supervision, unstructured tutorials and unmanaged time experienced by the students. There should be well-defined aims and fixed agenda designed by trained supervisors for quality supervision.

At last, there seems to be an absence of detailed and explicitly stated rules and regulations to regulate and restrict supervision behavior and supervision practice. The relevant rules for roles and responsibilities of both students and supervisors are too general and vague to operate. In some cases, more severe measures like contractual and legal solutions (Hockey, 1996; Philips and Pugh, 2010) can be resorted to.

According to Richard Hall, the essential elements of any pure form of bureaucracy in the west include the following attributes: "(1) A well-defined hierarchy of authority; (2) A division of labor based upon functional specialization; (3) A system of rules covering the rights and duties of positional incumbents; (4) A system of procedures for dealing with work situations (as cited in Bond 1991: 78). Consequently, the management style in U/C is non-bureaucratic in nature on the basis of the above mentioned discussion points.

\section{Conclusion}

In conclusion, the effectiveness of EFL research supervision needs to be enhanced. The non-bureaucratic nature of administrative system has caused the exhaustion and resistance of the supervisors on one hand, who are unable to do their teaching and research well with their hands full, and dissatisfaction with inadequate, unstructured and unmanaged supervision from the students on the other hand. The low efficiency is damaging to the quality of research and in turn supervisory relationship, which thus inhibits the professional development of individuals and growth of graduate education. A pro-supervising research community should be designed to enable its students to generate quality research outcome and its supervisors to focus on academic duties only instead of all-encompassing responsibilities.

The current perceptual research can be improved in the future by:

1. The interview should be conducted more systematically for the student and supervisor informants for three times so that the present data can be better triangulated by asking their confirmation of the complaints.

2. The number of interview questions should be narrowed down so that more focused questions can be asked for one question.

3. The number of interview informants can be reduced to 8 mainland supervisees and supervisors respectively. In this 
way, the workload of finding subjects, transcription of data, data analysis will be decreased to a large degree.

\section{Acknowledgements}

I would like to express my heartfelt gratitude towards all anonymous research informants from U/C, without whose continued support, cooperation and encouragement, this research would have been impossible.

\section{References}

Bond, M. H. (1991). Beyond the Chinese Face. Oxford/ New York/ Toronto Oxford University Press.

Dai, W. D. (2000). A talk about PhD supervision. Foreign Language Teaching and Research, 5(5), 385-386.

Dai, W. D., \& Wang, X. M. (2005). Collaborative-inquiry model in teaching for English postgraduates: definition, theoretical basis and application, Foreign Languages of China, 2(4), 12-16.

Dai, W. D., \& Wang, X. M. (2007). Reflections on research and academic principles of English postgraduates, Foreign Languages of China, 4(5), 9-13.

Dai, W. H. (2009). EFL disciplinary construction and graduate education. Foreign Language World, 6, 2-9.

Dornyei, Z. (2007). Research Methods in Applied Linguistics. Oxford: Oxford University Press.

European Institute of The London School of Economics and Political Science. Handbook for Research Degree Students, session 2011/2012, 1-34.

Gao, F. (2012). A development of research students' international horizon, problem consciousness and creativity. Degree and Graduate Education, 1, 7-10.

Hockey, J. (1996). A Contractual solution to problems in the supervision of $\mathrm{PhD}$ supervisor's role. Studies in Higher Education, 21(3), 359-371.

Hu, Z. L. (2002). Reflections on China's English education. Foreign Language Research, 3, 2-9.

Hua, M. (2000a). Interview with PhD supervisors-Professor Liu Runqing. Foreign Language Teaching and Research, 32(4), 307-311. http://dx.doi.org/10.1080/03075079612331381271

Hua, M. (2000b). Interview with PhD supervisors----Professor Hu Zhuanglin. Foreign Language Teaching and Research, 32(6), 456-460.

Li, C. S., \& Xu, B. F. (2006). History of Modern Foreign Language Education in China (In Chinese). Shanghai: Shanghai Foreign Language Education Press.

Lu, J. M. (2001). Informal comments on PhD candidates' supervision. Foreign Language Teaching and Research, 33(1), 69-72.

Peng, H. B. (2015). Assessing the quality of research supervision in mainland Chinese higher education. Quality in Higher Education, 21(1), 89-100. http://dx.doi.org/10.1080/13538322.2015.1049441.

Philips, E. M., \& Pugh, D. S. (2010). How to get a PhD: A Handbook for Students and Their Supervisors (5 ${ }^{\text {th }}$ edition). Open University Press

Richards, K. (2003). Qualitative Inquiry in TESOL. New York: Palgrave Macmillan. http://dx.doi.org/10.1057/9780230505056

Scollon, R., \& Scollon, S. (2000). Intercultural Relationship: A Discourse Approach. Beijing: Foreign Language Teaching and Research Press/Blackwell Publishers Limited.

Sun, Y. H. (2008). Viewpoints on reforming EFL graduate supervision model. China Higher Education, 13 \&14, 47-49.

Wang, S. (2008). Intercultural Communication Concerns: Interactions between Chinese Graduate Students and American Advisors in Educational Contexts (Unpublished PhD Degree Dissertation), Shanghai International Studies of University.

Wang, X. M. (2008a). EFL postgraduate evaluation and academic competence development. Journal of Liberation Army College of Foreign Studies, 31(3), 63-68.

Wang, X. M. (2008b). Self-access theory and academic competence development of EFL postgraduates. Foreign Language World, 3, 15-20.

Wang, X. M. (2009a). Curriculum design and academic competence of EFL postgraduates. Foreign Language World, 1 , 44-50.

Wang, X. M. (2009b). Analyzing the connotations and functions of EFL graduate supervisors from the perspective of 
academic competence development. Foreign Language World, 6, 43-49.

Wang, X. M. (2010). Cognitive Affective Analysis and Multi-dimensional Development of English Postgraduates' Academic Competence (in Chinese). Shanghai: Shanghai Foreign Language Teaching Press.

Wang, X. M. (2010). Reflections on Chinese EFL MA graduate education from the perspective of needs analysis of academic competence. Foreign Language World, 5, 67-74.

Wang, X. M. (2012). Connotations, categorizations and applications of English postgraduates' teaching materials. Foreign Language World, 4, 88-96.

Wang, X. M. (2013). A revisit to the connotation and development process of English postgraduates' academic competence. Contemporary Foreign Languages Research, 2, 32-36.

Wang, X. M. (2014). A survey on the current research competence of English postgraduates in foreign language universities. Journal of PLA University of Foreign Languages, 37(2), 18-24.

Wen, Q. F. (2002). Major problems and measures in MA graduate education. Degree and Graduate Education, 5, 21-24.

Wen, Q. F. (2008). Discussion on developing EFL postgraduates' advanced level thinking competence. Degree and Graduate Education, 10, 29-34.

Wen, Q. F., Ding, Y. R., Chen, X. R., \& Wang, W. Y. (2006). Building a learning community to improve the overall quality of postgraduate programs on applied linguistics for English majors. Chinese Foreign Language, 3(2), 11-13. http://dx.doi.org/10.13564/j.cnki.issn.1672-9382.2006.02.007

Wenger, E. (1998). Communities of practice: learning, meaning, and identity. New York: Cambridge University Press. http://dx.doi.org/10.1017/CBO9780511803932

Zhang, D. L. (2005). Exploration of reforming EFL graduate supervision model. Foreign Languages of China, 2(4), 8-11. http://dx.doi.org/10.13564 /j. cnki .issn.1672 -9382.2005.04.001

Zhang, S. J., \& Yang, Z. (2009). Education of EFL PhD program: problems and measures. Foreign Languages of China, $1,4-8$.

Zhu, X. L. (2005). Multi-dimensional explorations on EFL graduate education. Foreign Languages, 1, 77.

Zhu, Y. (2003). Research paper writing and research competence of graduate students. Foreign Language and Teaching, 7, 25-27.

\section{Notes}

Note 1. A pseudonym is used for the university under the study of the researcher in order to mask its true identity for the purpose of confidentiality and anonymity.

\section{Appendix: Selected interview questions}

1. How do you supervise your supervisees? / How are you supervised?

2. Have you ever compared or contrasted your supervision relationship with the others?

3. How do you manage your time? (For graduate students)

4. What roles are supervisors assumed to play? Decision-maker, booklist provider, academic/non-academic consultant, time-discipliner, methodology demonstrator, suggestions provider, editor, critical reviewer, financial problem solver and the like.

\section{$(\infty)$ EY}

This work is licensed under a Creative Commons Attribution 3.0 License. 